\title{
Neoliberal Cricketing Subjects in Contemporary India: The State-Market Dichotomy in Two Cricket Movies
}

\author{
Rakesh Ramamoorthy \\ Assistant Professor, Department of English, Mar Ivanios College (Autonomous), Kerala, India. \\ Email: rakeshmoorthy@gmail.com, https://orcid.org/0000-0002-2355-1054
}

\begin{abstract}
This essay examines the ways in which two popular cricket movies from India - the Hindi movie Iqbal (2005) and the Tamil movie Jeeva (2014) — validate the tenets of "roll-back neoliberalism" (Peck and Tickell 2002), an ideology that calls for the withdrawal of State-regulatedwelfare mechanisms in favour of free market capitalism. The protagonists of these movies are talented cricketers from underprivileged backgrounds, and they are excluded from regional and national teams by corrupt cricket board officials. This essay critiques a common story arc that these narratives share: the protagonists are quintessentially neoliberal entrepreneurial subjects who overcome the marginalization through adept exploitation of commercial potential of the sport. The argument is that the discursive delegitimization of State intervention in cricket, and the concomitant framing of the free market as a progressive and inclusive entity, are disempowering for the cricketing public. While a State-regulated sporting culture does have its exclusionary aspects, this essay contends, contrapuntally, that the neoliberal validation of the free-market rationale can be problematic in that it absolves the State of the responsibility of fostering an inclusive cricketing culture. This study thus offers a contingent and strategic endorsement of the Indian State's intervention in the nation's cricketing cultures.
\end{abstract}

Keywords: Indian cricketing nationalisms, neoliberalism, caste and cricket, Iqbal, Jeeva

The sport of cricket is no longer a paean to the English character, purportedly characterized by orderliness and fortitude, as Rev. Pycroft claimed in his legendary treatise The Cricket Field (p. 25). It is widely acknowledged that the sport of today is allied to neoliberal capitalism, and it is Indian cricket, more than any other, that embodies reigning ideology in its fullest spirit (Gemmell 2018; also see Gupta 2004, 2009; Majumdar 2007). Corporate nationalism, characterized by the "transnational capital's encroachment into the symbolic orchestration of national cultures" (Silk et al., 2004, p.7) is arguably the dominant ideology of contemporary Indian cricketing cultures. This essay is interested in the ways in which the symbolic tenor of Indian cricketing nationalisms is influenced by the ideology of neoliberalism. It analyzes two popular cricket movies, Iqbal (2005) and Jeeva (2014), and argues that these movies endorse a form of cricketing nationalism that validates the notion of roll-back neoliberalism. The cultural politics of these texts can be gleaned from a common arc of transformation that the eponymous protagonists undergo: Talented

This Open Access article is published under a Creative Commons Attribution Non-Commercial 4.0 International License (http://creativecommons.org/licenses/by-nc/4.0/), which permits non-commercial re-use, distribution, and reproduction in any medium, provided the original work is properly cited. For citation use the DOI. For commercial re-use, please contact editor@rupkatha.com. 
cricketers from underprivileged backgrounds (Iqbal is a deaf-mute boy from a poor agrarian family whereas Jeeva belongs to a lower caste, proletarian family) are kept out of the national team by corrupt, elitist cricketing administrators. However, they both metamorphosize into quintessentially neoliberal entrepreneurial subjects who achieve their goals through their adept negotiation of the cricket-industry nexus. Such a cricketing discourse is problematic in that it frames the free market as an egalitarian domain while simultaneously absolving the State of the responsibility of fostering inclusive cricketing nationalisms.

Thomas Lemke's (2001) seminal explication of Michel Foucault's work on neoliberal governmentality serves as a good entry point for the present discussion of the neoliberal withdrawal of the state. The neoliberal ideology endorses the intrusion of economic logic into the social sphere, "transpos[ing] economic analytical schemata and criteria for economic decision making onto spheres which are not, or certainly not exclusively, economic areas, or indeed stand out for differing from any economic rationality" (p.197). This involves a withdrawal of the state from many domains, for, "[n]eo-liberalism is a political rationality that tries to render the social domain economic and to link a reduction in (welfare) state services and security systems to the increasing call for 'personal responsibility' and 'self-care'" (p. 203). The ideal subject under neoliberalism is an entrepreneurial subject who competes in the open market, unlike classical liberalism,

[n]eoliberalism no longer locates the rational principle for regulating and limiting the action of government in a natural freedom that we should all respect, but instead it posits an artificially arranged liberty: in the entrepreneurial and competitive behaviour of economic-rational individuals. (200)

This aspect of neoliberalism resulted in the dismantling of the Keynesian Welfare State apparatuses in North America and Western Europe in the 1980s and is termed "roll-back neoliberalism" (Peck and Tickell 2002, p.388). The economic liberalization of 1991 resulted in such a roll-back in India, undermining the humanist imperatives of the erstwhile social democratic state (Joseph 2007). The cricket-industry nexus enabled by the liberalization paved way for India's emergence as the most significant media market for world cricket - it is estimated that $80 \%$ of the income of the ICC comes from India (Gemmell, 2018, p.199).

Whereas the neoliberal governmentality has tended to delegitimize affirmative action wherever it has operated, it is nobody's case that the State apparatus in India has been innocent of exclusiveness along caste, class, and gender lines. The Indian cricket has functioned as Ideological State Apparatuses, shoring up the legitimacy of the governments, a case in point being India's cricketing success being discursively associated with Indira Gandhi's authoritarian Emergency era regime (Guha, 2002, p.355). Furthermore, there is no gainsaying that corruption is rampant in the administrative structures of Indian cricket, just as the movies allege. This essay argues that that the movies Iqba/and Jeeva advocate a neoliberal conception of the Indian cricket hero by representing the free market as a progressive agent that empowers the subaltern cricketer to overcome the hurdles posed by the (allegedly corrupt) State apparatus. This trope is neoliberal in its endorsement of the withdrawal of the state from certain domains, resulting in the intrusion of market ideology and rationale into these domains (Brown 44). Neoliberalism's thrust on individualism is a ploy that renders the individual completely responsible for his/her success and 
failures, and dismisses the notion of welfarism (Lemke 201-2). The contention of the present study is that the 'corrupt State/progressive market' binary that is constructed in these narratives, and the resultant blanket delegitimization of State intervention in Indian cricket, is disempowering for the Indian cricketing public. This argument is informed by the assumption, derived from Mannathukkaren (2018), that, given the undeniably 'representative' status that the Indian national cricket team holds in the national imaginary, it is incumbent upon the State to ensure the inclusiveness of the nation's mainstream cricketing cultures. The assumption is that State apparatus can intervene, in sport and elsewhere, to ensure a certain degree of egalitarianism, albeit one that will be inevitably circumscribed by the hegemony of the State apparatuses.

\section{The Neoliberal Pitch in Iqbal and Jeeva}

The plot of Nagesh Kukkunoor's Iqba/is an inspirational rise of the underdog tale typical of sports movies. It shows how the eponymous protagonist - a deaf and mute boy from a nearly insolvent agrarian family - achieves cricketing success and fame, and becomes a member of the Indian national cricket team by virtue of his hard work and entrepreneurial orientation. A prodigiously talented fast bowler, Iqbal hones his craft by practising alone in the field while grazing the family's buffaloes and by furtively watching the nets practice at a prominent cricket academy. Guruji, the coach at the local academy and an influential figure in the Indian cricket firmament, comes to know of his talent through the efforts of Iqbal's younger sister Khadija, and accepts him into the academy. However, Guruji is forced to expel Iqbal from the academy when the latter clashes with Kamal, the star batsman of the academy and the son of an influential businessman. Though Iqbal is heartbroken, his spirit revives when a photo published in the Sports Star magazine helps him realize that Mohit, the village drunkard, used to be a well-known cricketer at the domestic level. Iqbal manages to overcome Mohit's initial reluctance through sheer persistence, and convinces him to cut back on his drinking and become his coach. Iqbal performs remarkably well at the trials for the Ranji trophy team but the wheeling and dealing in the cricket administration ensures that he is not selected for his home state of Maharashtra. The chief selector, however, is impressed by his bowling and helps him get a place in the relatively low-profile Andhra Pradesh team. Bolstered by Iqbal's extraordinary bowling skills, the traditionally weak Andhra team reaches the finals of the Ranji trophy. At this juncture, Mohit approaches Guruji with a request: There are credible rumours that a national selector will be watching the finals, and he requests Guruji to let the players' performance determine the selection. The ensuing conversation reveals that Mohit used to be Guruji's prize student and that Guruji's political manoeuvring had resulted in another player from a rich and influential family being selected to the Indian team ahead of Mohit. Guruji is unfazed by Mohit's accusations, and he argues that deal making has become an integral part of the sport of cricket. He maintains that great players have emerged through such deals and that even talented cricketers must await their turn. He says that the present Indian team needs a new batsman rather than a bowler, and discloses his intention of getting Kamal selected to the team.

Another significant development occurs on the first day of the Ranji trophy finals: Iqbal is approached by a representative of "Talent Partners", a sports management agency. The agent declares that his firm is committed to nurturing talent, that they have done extensive research on Iqbal, and offers to get him lucrative TV, public appearance, and advertisement deals in addition 
to a handsome signing bonus. He is embarrassed and beats a hasty retreat when Mohit, who witnessed the whole conversation, informs him that Iqbal is differently abled. The significant point, from the perspective of the present analysis, is that Mohit warns him that such people are dangerous and compares them to vultures. It is equally pertinent that Iqbal does not object to Mohit's opinion, and his sole response is to get Mohit to promise that he will be around to shield him from such influences. This indicates that he shares Mohit's disapproval of cricket's increasing nexus with the market and its promotional cultures.

The movie's initial critique of the agents of the 'cricket inc.' is pertinent because it sets up the subsequent discursive legitimization of the commercialization of cricket. Guruji approaches Iqbal with a deal on the penultimate day of the match. He reiterates his intention of getting Kamal selected to the Indian national team, and demands that Iqbal should underperform the next day, especially while bowling to Kamal. In return, Guruji offers him a cheque for twenty-five lakhs, and reminds him that the sum will enable him to retrieve his father's farm lands, which have been attached by the bank. Further, he promises that he will ensure that Iqbal is selected to the national team the following year. These promises are accompanied by the threat that should Iqbal refuse, Guruji would ensure that he will never play for India. Iqbal is left with little choice but to comply, and he intentionally bowls poorly the next morning.

A vital turning point occurs in the narrative in the form of a chance remark by Mohit (who is oblivious of Guruji's threats) during the lunch break which reminds Iqbal of having been approached by a representative from the players' agency. Iqbal seems to have an epiphany and disappears somewhere, returning only moments before the resumption of play. Iqbal bowls with zest during the post-lunch session and picks up five wickets. When the tea break is announced, the match is set for an exciting finish with Maharashtra needing eighteen runs for victory with just one wicket in hand. Guruji approaches Iqbal during the break, reminds him of their deal, and warns him against trying to double cross him. He demands that Iqbal should let Kamal finish his century and lead his team into victory. Iqbal is unmoved, and he employs "chakravyuh", Mohit's patented strategy of mind game, in order to dismiss Kamal, and thus wins the match for Andhra. An infuriated Guruji confronts Iqbal and accuses him of reneging on their agreement. Iqbal responds by tearing up Guruji's cheque into pieces and gesturing that there is no deal between them. Guruji retorts that Iqbal's actions will cost him his international career as well as the financial ruin of his family. At this point, the representative from Talent Partners appears, bearing contracts for Iqbal's signature and a cheque for fifty lakh rupees. It is revealed that Iqbal had approached the agent during the lunch break. Moreover, the legendary cricketer Kapil Dev - who, it turns out, had watched the match in his capacity as a selector for the national team - walks up to them, praises Iqbal's performance, and strongly hints that Iqbal has been selected for the national team. The movie ends with scenes of Iqbal making his debut for the India One Day International team.

The cultural politics of the text can be gleaned from the narrative choice of presenting the free market as a progressive alternative to corrupt and discredited state mechanisms. The plot of the movie initially presents the prevalent notion that the quick influx of money (an effect of the commercialization of sport) can be a corrupting influence on young cricketers, only to 'recode' the market as a liberating agent that empowers the subaltern cricketer to overcome the hurdles posed by the crooked administrators. It is significant that the decision to empower himself by exploiting his own commercial potential as a cricketing celebrity was taken by Iqbal without 
seeking advice from anyone else. Iqbal is thus depicted as a typically neoliberal entrepreneurial subject, characterized by his capacity for 'self-care'.

In Iqbal, the valorization of self-reliance is accompanied by a concomitant denigration of welfarism. One of the early scenes of the movie is that of Anwar selling off his motorcycle because he needs money to pay for the electricity required for farming. Saida, his mother, explains to Iqbal that Anwar is too proud to accept the free electricity offered by the government, thereby evoking a neoliberal discourse that looks down upon welfarism. Moreover, Anwar's opposition to cricket has neoliberal overtones. When Anwar bars Iqbal from playing for the Andhra team, Mohit attempts to convince him regarding the worth of a successful cricketing career. In the ensuing conversation, Anwar lambasts cricket as a sport that wastes time and hampers productivity. Here, and elsewhere in the movie, he is steadfast in his conviction that Iqbal should be a farmer, which will enable him to earn his livelihood and contribute to the growth of the nation. Anwar thus prioritizes the individual's responsibilities towards the state and discounts the notion that the citizen is entitled to support from the state. Anwar's neoliberal outlook is pertinent because Saida comments on multiple occasions that Iqbal has inherited his pride and stubbornness from Anwar. As the preceding discussion has established, Iqbal's climactic triumph is in line with this neoliberal rationale: while he represents the Indian national cricket team, which has strong symbolic affiliations to the Indian state, the associated function of harnessing cricketing talent was made possible - in part — due to the individual's astute engagement with the market rather than as a result of the structural support offered by the nation's cricketing firmament.

Iqbals endorsement of the 'rolling back' of the State is partial. The narrative endorses the basic premise of roll-back neoliberalism by asserting both the corrupt nature of the State apparatus and the effectiveness of market forces. However, it stops short of explicitly advocating a roll-back of the State apparatus from cricket administration. Such a blatant endorsement of neoliberalism can be seen in Suseendhiran's movie Jeeva. Jeeva addresses the elephant in the room that popular cricket narratives often choose to sidestep: the credible allegations that casteism plays a major role in the selection of the Indian national cricket team (see Anand, 2003). However, it is also a problematic narrative, for it proposes that the privatization and commercialization of cricket can empower professional cricketers to negotiate the caste-based discrimination.

The whole narrative is a monologue by the protagonist Jeeva, a talented cricketer who belongs to the Dalit community. Jeeva works hard at improving his game and yearns to play for the national side. When Jeeva's team, the Phoenix Cricket Club, reaches the finals of the First Division cricket tournament, they are pitted against the DCA club, the reigning champions. At this point, the audience are introduced to the primary antagonist of the tale: Parthasarathy, a highcaste Brahmin, who is the owner of the DCA club and an important figure in the Tamil Nadu Cricket Board. Though Jeeva's club narrowly loses to the DCA, Parthasarathy is impressed by Jeeva's batting and offers him a place in his club. However, Jeeva is put off by the club's reputation - it is implied that the coach of the Phoenix Cricket Club had told his players regarding Parthasarathy's habit of exerting influence in order to get his players selected to higher level teams - , and decides to further his career by performing well at the domestic tournaments such as the Under-22 and Ranji trophy tournaments. Jeeva thus places his faith in the State apparatus. At the selection 
committee meeting, Parthasarathy reluctantly agrees to include Jeeva and his close friend Ranjith in the Ranji trophy team when one of the selectors argues that ignoring their remarkable performance would trigger a media furore. However, their joy is short lived as their coach warns them of the casteism that they will have to negotiate:

... It is not enough to just get selected to Ranji. You should also get the chance to play. There is a lot of politics around here. Sixteen players from Tamil Nadu have been selected to the Indian team till date. Of those, fourteen belong to Parthasarathy's community. Nobody from other communities have been selected in the last twenty years. Because, right from the selection committee to the peon, their people occupy all the positions. As far as the Ranji is concerned, they would already have selected eleven players. They will play the maximum number of matches. You will be made to sit on the sidelines. They will make you bitter, make you wonder why you chose cricket for a career. They will play their regular players on good batting pitches. You will be made to play on tough, bowler friendly pitches. You will have to prove yourselves even if you are given a go under very tough circumstances. (01:28:09-01:30:00; My translation)

While the statistics cited by the coach are not accurate (more than sixteen Tamil Nadu players have represented India); but the issue that he raises - Brahmin domination in Indian cricket in general, and Tamil Nadu cricket in particular — is of great relevance. Ramachandra Guha's account of the struggles of Palwankar Baloo, a prodigiously talented Dalit cricketer who played in the Bombay Pentangular tournaments in colonial Bombay, in his seminal work $A$ Corner of a Foreign Field (2002), is a testament to the ways in which caste has shaped the Indian cricketing cultures from its nascent stages onwards (pp.81-123). Siriyavan Anand, in his Brahmans \&Cricket (2003) has offered a sharp critique of the problematic representation of caste in the movie Lagaan (2001). $\mathrm{He}$ has outlined the disproportionate representation of Brahmins in Indian cricket teams, providing statistical evidence with regard to eight teams that have represented India during the period from 1971 to 2003 (pp.59-60). Anand also cites Ramachandra Guha's observation, in his The States of Indian Cricket (2005), that Tamil Nadu cricket was so dominated by Brahmins that the tussle was between two factions, the Iyers and the Iyengars, with the former resenting the latter's over representation in the state's sides (p.56). Akshay Ramesh's essay, "Is Caste an indispensable member of Tamil Nadu Cricket Association's squad?"(2015), published in the online publishing platform, Medium, presents diverse perspectives on the issue of casteism in Tamil Nadu cricket, quoting allegations of caste bias as well as denials of the same. The article uses Jeeva as an entry point into the discussion, and notes that when a player (Jeeva, and not Ranjith as the article mistakenly claims) emerges as the top scorer in a match, Parthasarathy tries to see whether he is wearing the sacred thread. The reference is to the scene showing the post-match presentation ceremony of the finals of the First Division Tournament, when Parthasarathy feels around for the sacred thread under the guise of patting him on the back. The article also carries a quote from Gunalan Paneer, a young cricketer from Chennai, attesting to the widespread nature of this practice of 'feeling for the thread'.

The coach's apprehensions turn out to be well-founded, and Jeeva and Ranjit find themselves benched throughout the Ranji season. They do play a few matches in the succeeding season; but these opportunities turn out to have been part of a conspiracy. The State team's coach plays them in three matches and makes them bat low down the order, thereby limiting their 
scoring potential. At the next year's selection meeting, their averages are found to be inferior to that of two other players who had played in seven matches, and they are dropped from the squad. The movie thus presents a blatant Brahminical conspiracy. Both Parthasarathy and Raghavan, the coach, sport caste marks on their forehead identifying themselves as Iyengar Brahmins. Similarly, the players who replace Jeeva and Ranjith — Sriram and Seshagopalan - have typically Brahmin names. An enraged Ranjith barges into the office of the cricket board with Jeeva in tow and confronts Raghavan and Parthasarathy. In the heated debate that ensues, Ranjith explicitly accuses them of deliberately damaging the career of many players, such as that of himself and Jeeva, in order to sustain the Brahmin domination of Tamil Nadu cricket. He demands answers from Parthasarathy , "... Be true to your conscience when you answer this: has there been not even one talented player from among us [the 'lower caste' communities] in all these years?" ?" (01:38:5001:39:06; my translation). They are unceremoniously thrown out of the office premises by the security. Both Jeeva and Ranjith are convinced that their cricketing careers are over, as Parthasarathy will carry out a vendetta against them. Ranjith is heartbroken and commits suicide.

This credible tale that offers a stringent critique of casteism in cricket is followed by a story arc that presents a miraculous and problematic transformation of Jeeva's cricketing fortunes, wherein a free market and a neoliberal subjectivity is proposed as a progressive alternative to the Brahminical order. He is selected to play for "Rajasthan Riders", a franchise in the CPL, a newly formed cricket league. It is revealed that his name was recommended by Irfan, a former Indian player and the captain of the Rajasthan Ranji team, who was impressed by Jeeva's performance against Rajasthan during his brief Ranji stint. The coach delivers the good news to Jeeva, and says the following words:

Till now, you were playing in front of the selectors. For the first time, you are going to play in front of the audience. Crores of people will watch you play. If you can prove yourself in this, nobody can stop you from being selected to the Indian team. Nobody should suffer like Ranjith. (01:54:29-01:54:46; My translation)

At work here is a capitalist discourse which attributes democratic ethos to the media spectacles of contemporary cricket. Not only is the market presented as a benevolent entity which offers a platform for the showcasing of cricketing talent; but it is also presented as an inclusive alternative to the elitist, Brahminical administrative bodies of cricket.

In this climactic moment, the monologue that constituted the whole movie turns out to have been a statement issued to multiple media outlets in his capacity as a member of the Indian team. This dovetails with the validation of the commercialization of cricket, for the insinuation is that his critique of casteism in cricket has been has been enabled by his stature as a celebrity cricketer. He says that he would never have made it to the Indian team if it were not for the "magic" of being selected by the CPL. While expressing his indebtedness to various people, he places special emphasis on Ranjith, "who became a scapegoat of politics" (my translation). Jeeva says,

In every other country, sportsmen play and fail. It is only in our country that they are losing without even getting a chance to play. I could face issues with my future career because I have spoken out about the politics that exist in cricket. But I am not worried about that. 
The politics can change only if selectors no longer pick the players. It should be up to the audience to select the players. (01:56:09-01:56:29; My translation)

In keeping with the ideological slant of the narrative, the triumphant images with which the movie closes are that of Jeeva's phenomenal CPL debut and not that of his international debut. In what is virtually the last moment of the movie, as Jeeva celebrates his half century, the camera shows the disgruntled expressions of Parthasarathy and Raghavan in the stands.

Thus, in both Iqbal and Jeeva, (realistic) critiques of the corrupt administrative structures of Indian cricket co-exist with a concomitant valorisation of the allegedly benevolent and progressive nature of the cricket industries. Jeeva's proposal that the state should withdraw from the selection of cricket teams is inimical to the fostering of an inclusive cricketing culture, for it amounts to the 'privatization' of the national cricket team. The audience's 'selection' of the team would be shaped by the mediatisation of cricket and cricketing stars, regardless of how such a process is conceived. It follows that the media-industry nexus would have considerable sway in the selection of the national team. The movie presents the CPL as a benevolent project that has the best interests of Indian cricket at heart and is committed to acknowledging talent and excellence. Such conceptions of inclusive meritocracy are widely discredited in the sphere of sports and elsewhere, for they discount the significance of privilege and assume the existence of a level playing field (Carrington, 2007, p.4; also see Rottenberg, 2018). Moreover, Jon Gemmell's reading of the rise of neoliberal ethos in contemporary cricket, in his book Cricket's Changing Ethos (2018), indicates that the movie's celebration of a commercialized cricketing culture is factually untenable. Though Gemmell concedes that the Indian national cricket team has become marginally more inclusive in terms of social class and caste in the era of neoliberalism (pp.205-6), he offers a trenchant critique of the new cricketing ethos. Citing Chris Rumford, he points out that T20 leagues merely 'hire' the services of players whose talents have been nurtured by various cricket boards and that they are indifferent towards the development of the national side (p.214).This argument can, of course, be critiqued for prioritizing the cause of cricketing nationalism above the cricketer's rights as professionals. However, the interesting takeaway for the present discussion is that private franchises are not committed to the nurturing of an inclusive cricketing culture. Gemmell quotes a comment by a franchise owner to the effect that he is a businessman with no interest in cricket, and outlines the adroit ways in which the IPL monetizes cricket (p.217-8). He argues that many of the stated objectives of the IPL including that of being nurseries for fresh talent has turned out to be spurious (p.218). He further points out that the BCCI's embargoing of the rival Indian Cricket League (which resulted in the BCCI being fined by Competition Commission of India) is a deviation from the tournament's purported commitment to free market principles (p.218). Jeeva's narrative is, therefore, deeply problematic. Rather than democratizing the cricketing culture, the withdrawal of the state is likely to disenfranchise the subaltern cricketers as the state would no longer be even nominally responsible for ensuring social justice in the sphere of cricket.

\section{Conclusion: Cricketing Nationalism and the State}

The above analysis has critiqued the cultural politics of two popular Indian cricket movies from a standpoint that endorses, albeit contingently and strategically, a State-regulated sporting culture. 
The recent calls for affirmative action in cricket have underscored the possibility of the State apparatus fostering an inclusive sporting culture. Gaurav Bhawnani and Shubham Jain (2018) make the case for caste-based reservation in teams as a means of addressing the structural inequalities that pervade the cultures of Indian cricket. They draw upon Boria Majumdar's contention that pre-Independence cricket used to be more inclusive of lower castes and that the subsequent exclusion was a result of princely patronage of cricket giving way for corporate patronage, for the latter preferred to employ well-educated cricketers who could discharge their official duties after retirement. This enables them to argue that there are systemic barriers to the entry of lower castes into the cricket teams (51-2). They point out that the Indian women's cricket team which reached finals in the 2017 Women's Cricket World Cup was far more diverse in terms of caste than its male counterpart, and attribute this to the fact that the Indian Railways, an organization that follows caste-based reservation policies, is the chief employer of women cricketers (52). Their study makes a case for the introduction of quotas along the lines of those implemented for black players in South Africa, pointing out that the phased introduction of reservations starting from the lower levels ensured the availability of a pool of talented black cricketers by the time the policy was implemented in the national team selection (54). They point out that the absence of any dip in the team's performance largely belied the contention that quotas can undermine quality (54).

In the same vein, Nissim Mannathukkaren's article in The Hindu, "Why We Need Reservations in Cricket" (2018) refers to the work of Bhawnani and Jain, and underscores the need for affirmative action in Indian cricket. He is dismissive of the glib assertion that the West has progressed as it is not hampered by quotas, and points out that developed Western nations such as USA, Canada, and Australia do have affirmative action policies in sports and elsewhere. He establishes the need for reservations on the grounds of cricketing nationalism when he writes: "If one plays as an Indian, is it not one's social responsibility to include as many sections into the team as possible? What is a "national" cricket team when members largely belong to a few social groups?". Mannathukkaren's observation needs to be read in the light of the fact that cricket enjoys a de facto 'official' status in India, being associated with both the nation (as reflected by the symbolism of the sport) and with the State apparatus (as evidenced by the court ruling that matches of national importance should be broadcast by the state-run Doordarshan, notwithstanding the presence of a channel which has won the telecast rights). It follows that the 'official' sport also carries the burden of social inclusion. Bhawnani and Jain have observed that the Supreme Court underlined the 'statist' nature of the BCCI, thereby endorsing the legal validity of judicial intervention for the sake of affirmative action in Indian cricket (54-5). This indicates that it is possible for the state to ensure that cricket is an inclusive sport accessible to the marginalized sections of the citizenry, including the differently abled and the lower castes. This is not to argue that cricket has to be mandatorily seen as a nationalist sport. The contention, rather, is that given the ubiquity of the associations between cricket and Indian nationalisms in popular as well as official discourses, the State has the responsibility of ensuring that the national imaginary constructed through sport should be representative of the nation as a whole.

The progressive potential of such State-regulated inclusiveness has been demonstrated by some of the reforms effected and/or recommended by the Lodha committee. A key task of the committee - appointed by the Supreme Court of India in the aftermath of the allegations of 
illegal betting and spot-fixing during the IPL 2013 - was to recommend reforms in the administration and organization of cricket in India. While some of the recommendations of the committee are discriminatory (such as the condition that those above seventy years of age are ineligible to become the office bearers of the states and the BCCI), some others have been progressive and inclusive in nature. A case in point would be the remedying of the previous situation in which nine states were not represented in the BCCI, and two states, Maharashta and Gujarat, had three full members each. The report's insistence that, "[i]t is imperative that all players across the country have opportunities to represent their States and Zones and then the national team" (Lodha et al., 2015, p. 23), resulted in all twenty-nine states fielding teams in the Ranji trophy of 2018-19. Similarly, the Lodha committee report has recommended the formation of a "Players' Association" comprising all ex-cricketers which would have the right to nominate two members, one male and one female, to the apex council of the BCCI. The stated intention of this move is to aid the players' situation and enable them to voice their concerns (p.43). It is in the light of such potentialities that one should read this study's argument that the goal of inclusive cricketing nationalism(s) is poorly served by the movies' valorization of self-reliant neoliberal cricketing subjects who overcome systemic hurdles by exploiting the possibilities offered by the free market.

\section{References}

Anand, S. (Ed.) (2003). Brahmans \& Cricket: Lagaan's Millennial Purana and Other Myths. Navayana.

Bhawnani, Gaurav and Shubham Jain. (2018). Does India Need a Caste-based Quota in Cricket? Drawing Parallels from South Africa. Economic \& Political Weekly 53 (21): 50-7.

Brown, Wendy. (2005). Neoliberalism and the End of Liberal Democracy. In Edgework: Critical Essays on Knowledge and Politics. Princeton UP. 37-59.

Carrington, Ben. (2007). Sport and Race. In George Ritzer (Eds). The Blackwell Encyclopedia of Sociology. Wiley Online Library.

Gemmell, Jon. (2018). Cricket's Changing Ethos: Nobles, Nationalists and the IPL. Palgrave McMillan.

Gowariker, Ashutosh. (Director). (2001). Lagaan [Film]. Aamir Khan Productions.

Guha, Ramachandra. (2002). A Corner of a Foreign Field: The Indian History of a British Sport. Picador.

Guha, Ramachandra. (2005). The States of Indian Cricket: Anecdotal Histories. Permanent Black.

Gupta, Amit. (2004). The Globalization of Cricket: The Rise of the Non-West. International Journal of the History of Sport 21(2), 257-276.

Gupta, Amit. (2009). India and the IPL: Cricket's Globalized Empire. The Round Table 98 (401), 201-211.

Kukunoor, Nagesh. (Director). (2005). Iqbal [Film]. Mukta Arts.

Joseph, Sarah. (2007). Neoliberal Reforms and Democracy in India. Economic and Political Weekly 42(31), 3213-3218.

Lemke, Thomas. (2001). 'The Birth of Bio-Politics':Michel Foucault's Lecture at the Collège de France on Neo-liberal Governmentality. Economy and Society 30(2), 190-207. 
Lodha R.M., Ashok Bhan, and R.V. Raveendran. (2015, 18 December) Report of the Supreme Court Committee on Reforms in Cricket. The Hindu. https://www.thehindu.com/multimedia/archive/02682/volume_cover1_2682991a.pdf

Majumdar, Boria. (2007). Nationalist Romance to Postcolonial Sport: Cricket in 2006 India. Sport in Society 10(1), 88-100.

Mannathukkaren, Nissim. (2018, March 27). Does Indian Cricket Need Quotas? The Hindu. https://www.thehindu.com/opinion/op-ed/does-indian-cricket-need-quotas/article23357932.ece

Peck, Jamie and Adam Tickell.(2002). Neoliberalizing Space. Antipode 34 (3), 380-404.

Pycroft, James. (1859). The Cricket Field, or The History and Science of Cricket. Mayhew and Barker.

Ramesh, Akshay. (2015, April 15). Is Caste an Indispensable Member of Tamil Nadu Cricket Association's Squad. Medium. https://medium.com/@iamnotakshayr/is-caste-an-indispensable-member-oftamil-nadu-cricket-academy-s-squad-c42182d562ad

Rottenberg, Catherine. (2018). Neoliberal Meritocracy. [Review of Against Meritocracy: Culture, Power and Myths of Mobility, by Jo Littler]. Cultural Studies 32 (6), 997-9.

Silk, Michael, David L. Andrews, and C.L. Cole. (2005). Corporate Nationalism(s): The Spatial Dimensions of Sporting Capital. In Michael Silk, David L. Andrews, and C.L. Cole (Eds.,) Sport and Corporate Nationalisms. (pp.1-12). Berg.

Suseenthiran. (Director). (2014). Jeeva (2014). Show People.

Dr Rakesh Ramamoorthy works as Assistant Professor in the Department of English, Mar Ivanios College (Autonomous), Kerala, India. His doctoral thesis was a study of contemporary Indian and Pakistani cricket narratives from a Cultural Studies perspective. His essays have appeared in The Explicator, The Wiley-Blackwell Encyclopaedia of Postcolonial Studies, and The Palgrave Encyclopaedia of Imperialism and Anti-imperialism. 